\title{
Reconstrucción computacional de andamios para ingeniería de tejidos
}

\author{
C. SANDINO, M.P. GINEBRA*, J.A. PLANELL, D. LACROIX. \\ Institut de Bioenginyeria de Catalunya (IBEC). \\ *Dept. de Ciencia de los Materiales e Ing. Metalúrgica, Universitat Politècnica de Catalunya.
}

\begin{abstract}
Resumen
La caracterización de biomateriales se sirve cada vez más técnicas no destructivas de obtención de imágenes. Estás técnicas pueden ser aplicadas tanto in vitro como in vivo con una resolución que depende del tamaño de la muestra y de la técnica utilizada. Una de las técnicas más utilizadas, por su alta resolución, es la micro tomografía axial computerizada ( $\mu$-TAC).

El objetivo de este estudio fue caracterizar andamios para ingeniería de tejidos óseos en términos de su arquitectura y porosidad usando reconstrucciones computacionales a partir de microtomografía y generar mallas tridimensionales para modelos de elementos finitos. Imágenes de dos materiales con morfología diferente fueron utilizadas. Un andamio de cemento de fosfato de calcio y un andamio de vidrio biodegradable poroso fueron escaneados con una resolución de 7,8 x 7,8 x 12,2 $\mu$ m, para realizar posteriormente una recontrucción informática tridimensional y un mallado para análisis con el método de los elementos finitos. Se calculó la porosidad y se evaluó la interconectividad visualmente.

No se encontraron grandes diferencias entre los dos andamios al calcular la porosidad y la interconectividad (18\% para el cemento y $23 \%$ para el vidrio), sin embargo en las reconstrucciones tridimensionales se observaron grandes diferencias en la distribución de los poros dentro de los andamios.
\end{abstract}

Palabras clave: Andamio, modelos 3D, micro-TAC, mallado.

\begin{abstract}
The characterization of biomaterials employs increasingly non-destructive imaging techniques. These techniques can be applied both in vitro and in vivo, with a resolution dependent on the size of the sample and the employed technique. One of the most used techniques, due to its high resolution, is the axial computer microtomography $(\mu-C T)$.

The objective of this study was to characterize scaffolds for tissue engineering in terms of its architecture and porosity using computer reconstructions from microtomography and to generate $3 D$ meshes for finite element modeling. Images of two materials with different morphology were utilized. A scaffold of calcium phosphate cement and another scaffold and a scaffold of porous biodegradable glass were scanned with a resolution of $7.8 \times 7.8 \times 12.2 \mu \mathrm{m}$, to carry out subsequently a 3D computer reconstruction and meshing. The porosity was calculated and the interconnectivity was evaluated visually.

No relevant differences were found between the two scaffolds upon calculating the porosity and the interconnectivity (18\% for the cement and 23\% for the glass), nevertheless in the three-dimensional reconstructions large differences in the distribution of the pores inside the scaffolds were observed.
\end{abstract}

Keywords: Scaffold, 3D modeling, micro-CT, meshing.

\author{
Correspondencia: \\ Clara Sandino. \\ Institut de Bioenginyeria de Catalunya (IBEC). \\ Biomecànica i mecanobiologia \\ C. Baldiri Reixac, 4 Torre I. Planta 10. \\ 08028 Barcelona \\ E-mail: clara.sandino@upc.edu
}




\section{Introducción}

La finalidad de los andamios en el campo de la ingeniería de tejidos es servir de soporte a las células para que se proliferen y se diferencien, por lo tanto su diseño y desarrollo debe considerar factores biológicos y físicos, entre los cuales se encuentran las propiedades estructurales. La arquitectura de los andamios debe (1) proporcionar a las células suficiente espacio para cumplir su función de generar nuevo tejido, (2) permitir el paso de fluido para transportar células, nutrientes y oxigeno, y para eliminar desechos y (3) soportar las cargas mecánicas necesarias para estimular las células $[1,2]$.

Entre las propiedades estructurales más importantes se encuentran la porosidad, la ínterconectividad entre los poros, el área superficial específica, y la distribución del tamaño de los poros [3]. A mayor porosidad, mayor espacio disponible para que las células formen nuevo tejido y menor cantidad de material extraño introducido en el organismo. La interconectividad entre los poros es necesaria para permitir el paso del fluido que como se dijo anteriormente transporta las células, los nutrientes y el oxigeno. Todos los poros deberían estar abiertos e interconectados. El área superficial específica representa el área por unidad de volumen disponible para que las células se adhieran y formen nuevo tejido.

Los métodos tradicionales para caracterizar materiales desde el punto de vista estructural, pueden ser destructivos, como la porosimetría de mercurio, que genera un histograma para el tamaño de poros interconectados dentro de los andamios, pero que llena el material de mercurio dejando las muestras inutilizables para otro tipo de estudios, o la microscopía que permite observar la estructura del material pero es necesario cortar las muestras para poder observar las regiones internas.

Mediante micro Tomografía Axial Computarizada ( $\mu$-TAC) se obtienen imágenes transversales de los andamios sin destruirlos. Estas imágenes se superponen y se obtienen reconstrucciones computacionales en 3D de las muestras que permiten no sólo estudiar la arquitectura de los materiales $[4,5]$ sino generar mallas para estudios de Elementos Finitos (EF) que serán útiles más adelante para el análisis de sus propiedades biomecánicas [6, 7].

El objetivo de este estudio es, a partir de imágenes de micro TAC, reconstruir andamios en 3D utilizando el programa Mimics (Materialise Software) para analizar las propiedades estructurales más importantes y generar mallas para modelos de
EF. Se determinan los parámetros de mallado adecuados para obtener modelos de EF que se aproximen, de la mejor manera posible, a la arquitectura real de los andamios. Para esto se comparan mallas de superficie con diferente número de elementos.

\section{Materiales y Métodos}

\section{Materiales}

Se utilizaron andamios de $6 \mathrm{~mm}$ de diámetro y $12 \mathrm{~mm}$ de altura, de dos materiales biodegradables y porosos: (1) cemento basado en fosfato de calcio CaP y (2) vidrio cerámico tipo $\mathrm{Na} 2 \mathrm{O}-\mathrm{CaO}$ $-\mathrm{P} 2 \mathrm{O} 5$ - TiO2.

Para la preparación de los andamios de cemento por un lado se calienta una mezcla de CaHPO4 y $\mathrm{CaCO} 3$ a $1400^{\circ} \mathrm{C}$, se enfría rápidamente en aire, se muele hasta tener un tamaño de poro medio de $6,21 \mu \mathrm{m}$ y se añade un $2 \%$ en peso de hidroxiapatita precipitada. Por otro lado se disuelve polvo de albumen en agua generando una solución del $12 \%$ en peso que se mezcla hasta formar espuma. El polvo de fosfato de calcio diluido en agua destilada $(0,35 \mathrm{~mL} / \mathrm{g})$ se mezcla con la espuma de albumen y se introduce en moldes de teflón que son inmersos en una solución de Ringer a $37^{\circ} \mathrm{C}$ durante 7 días [8]. Para la elaboración de los andamios de vidrio se muelen partículas de vidrio hasta obtener un tamaño de grano que varía entre 0,1 y $100 \mu \mathrm{m}$ y se mezcla homogéneamente con clara de huevo [9].

\section{Micro Tomografia Axial Computarizada}

Un andamio de cada material (cemento y vidrio cerámico) fue escaneado usando un $\mu \mathrm{TAC} X$ Tek HMX225 (Digisens) con una resolución de $7,8 \times 7,8 \times 12,2 \mu \mathrm{m}$. Se tomaron 501 imágenes de cada muestra (Fig. 1)

\section{Reconstrucción en $3 D$}

Utilizando el programa Mimics se sobrepusieron las imágenes de $\mu \mathrm{TAC}$ y se reconstruyó la geometría de los andamios en 3D (Fig. 2). En Mimics se agrupan los píxeles por tonos de gris, estos conjuntos de píxeles en 3D son llamados máscaras. En los materiales estudiados los píxeles de color gris y negro corresponden a la fase sólida, y los de color blanco a los poros. Inicialmente se generaron dos mascaras una para la fase sólida del material y otra para los poros (Fig. 3). Para separar los poros cerrados de los interconectados se seleccionó la región conectada de la máscara de poros. Entonces se generaron dos nuevas máscaras una para los poros cerrados y otra para los poros interconectados. 


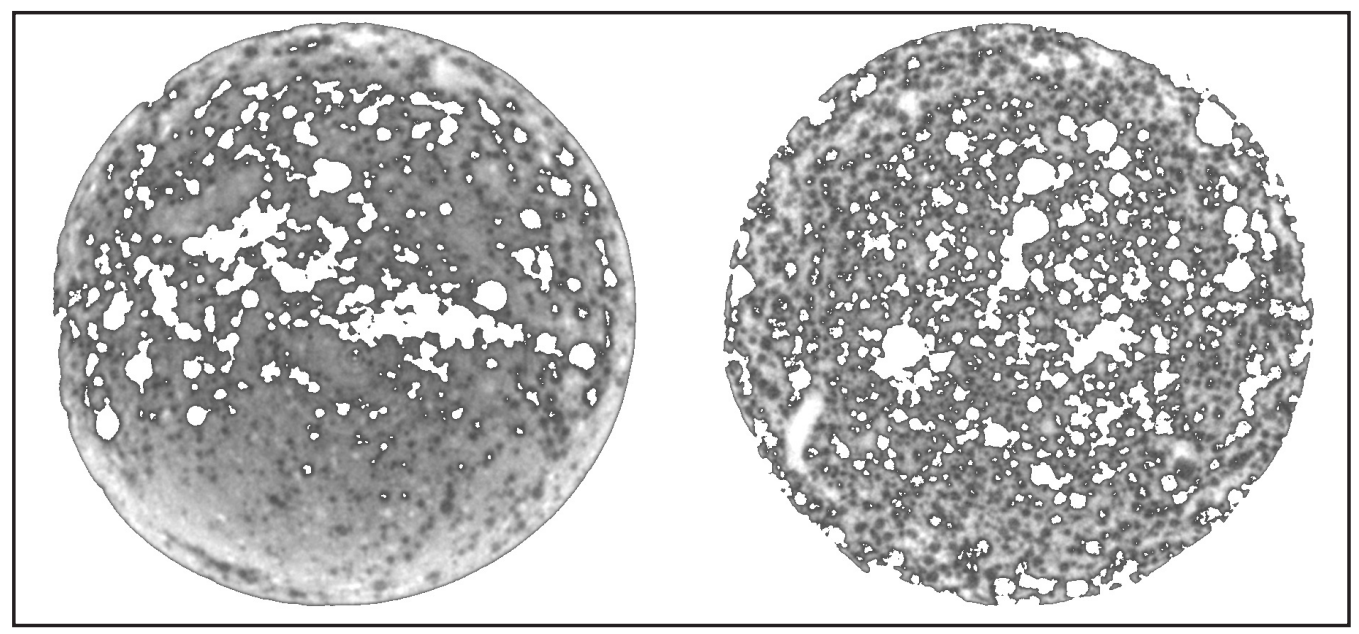

Figura 1. Imagen transversal del andamio (izquierda: cemento; derecha: vidrio).

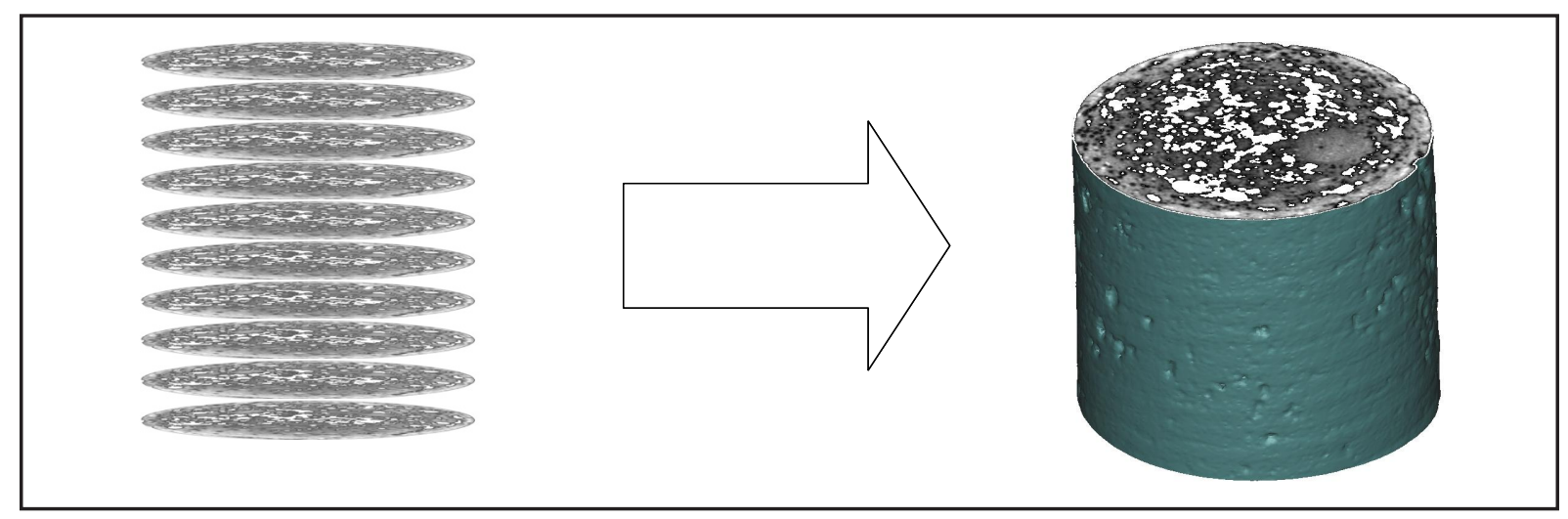

Figura 2. Reconstrucción en $3 \mathrm{D}$ de la geometría de los andamios a partir de $\mu \mathrm{TAC}$.

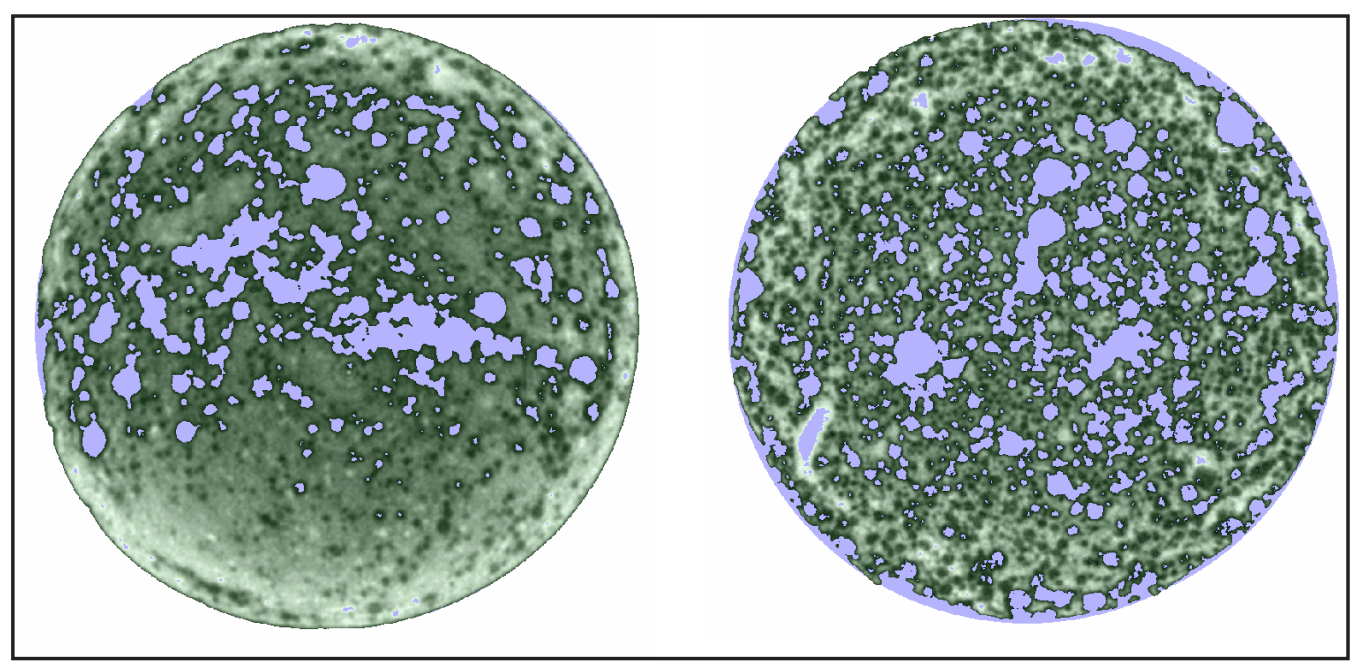

Figura 3. Mascaras de la fase sólida en gris oscuro y de los poros en gris claro (Izquierda: Cemento; Derecha: Vidrio). 


\section{Caracterización Estructural}

La porosidad se calculó como el porcentaje en volumen del espacio ocupado por los poros respecto al volumen aparente del andamio:

$$
\text { Porosidad }=\frac{\text { Volumen Poros }}{\text { Volumen Aparente }} \cdot 100 \%
$$

La interconectividad se calculó como el porcentaje en volumen del espacio ocupado por los poros interconectados respecto al volumen aparente del andamio:

Interconectividad $=\frac{\text { Volumen Poros Interconectados }}{\text { Volumen Aparente }} \cdot 100 \%$

El área superficial específica se calculó como el área de la superficie de los poros del andamio sobre el volumen aparente del andamio:

$$
\text { Area Superficial Especifica }=\frac{\text { Area Superficie }}{\text { Volumen Aparente }}
$$

La forma y la distribución del tamaño de los poros fueron evaluadas visualmente.

\section{Mallado}

En Mimics se construyeron mallas de triángulos sobre la superficie de las máscaras. La calidad de una malla, es decir la fidelidad con que representa la máscara, está relacionada con el número de triángulos utilizados. A mayor número de triángulos utilizados, mayor calidad en la representación de la máscara. Esta calidad se controla con el número de píxeles utilizados para construir la malla y el número de iteraciones que se realizan en el proceso de mallado. Se generaron mallas superficiales de la fase sólida del andamio de cemento usando las tres calidades (alta, media y baja) predeterminadas por el programa. Una vez optimizado el tamaño en sección plana, se procedió a realizar un mallado tridimensional para la fase sólida y líquida en Patran (MSC software, CA-USA).

\section{Resultados}

Para el andamio de cemento se calculó una porosidad del 18\%, de los cuales el 16\% corresponde a poros interconectados y el $2 \%$ a poros cerrados, mientras que para el andamio de vidrio se calculó una porosidad del $23 \%$, de los cuales $21 \%$ corresponde a poros interconectados y $2 \%$ a poros cerrado. El área superficial específica calculada para el cemento es de $4,87 \mathrm{~mm} 2 / \mathrm{mm} 3$ y para el vidrio de $6,85 \mathrm{~mm} 2 / \mathrm{mm} 3$ (Tabla 1 ).

La distribución de los poros a través del andamio y la interconectividad entre éstos es mejor para el andamio de vidrio que para el de cemento. En el andamio de vidrio se encuentran poros interconectados a través de toda la muestra, lo que no sucede en el andamio de cemento, en donde se observan regiones sin poros y regiones con alta concentración de poros cerrados (Fig. 4).

Al realizar cortes transversales de las reconstrucciones en 3D, para el andamio de cemento en los extremos se encuentran regiones extensas sin poros, gran cantidad de poros cerrados y sólo algunos poros interconectados. Los poros del andamio de vidrio estudiado se encuentran bien distribuidos a través del material, se observa gran cantidad de poros interconectados en todas las regiones del andamio y pocos poros cerrados (Fig. 5).

La distribución del tamaño de los poros no es uniforme en ninguno de los dos casos. En el andamio de cemento es difícil estimar visualmente un tamaño de poro medio dado que varía mucho de una región a otra. En una mitad del andamio se encuentran poros más grandes que en la otra mitad. Se observan poros entre $15 \mu \mathrm{m}$ y $1,37 \mathrm{~mm}$ de longitud aproximadamente (Fig. 6). En el andamio de vidrio se encuentran poros entre $22,5 \mu \mathrm{m}$ y $2,33 \mathrm{~mm}$ de longitud. La mayoría de los poros tienen un tamaño aproximado entre 184 y $533 \mu \mathrm{m}$. (Fig. 7)

\begin{tabular}{|c|c|c|}
\hline Material & Cemento & Vidrio \\
\hline Porosidad & $18 \%$ & $23 \%$ \\
\hline Poros interconectados & $16 \%$ & $21 \%$ \\
\hline Área superficial específica & $4,87 \mathrm{~mm}^{2} / \mathrm{mm}^{3}$ & $6,85 \mathrm{~mm}^{2} / \mathrm{mm}^{3}$ \\
\hline
\end{tabular}

Tabla 1. Propiedades estructurales de los andamios. 


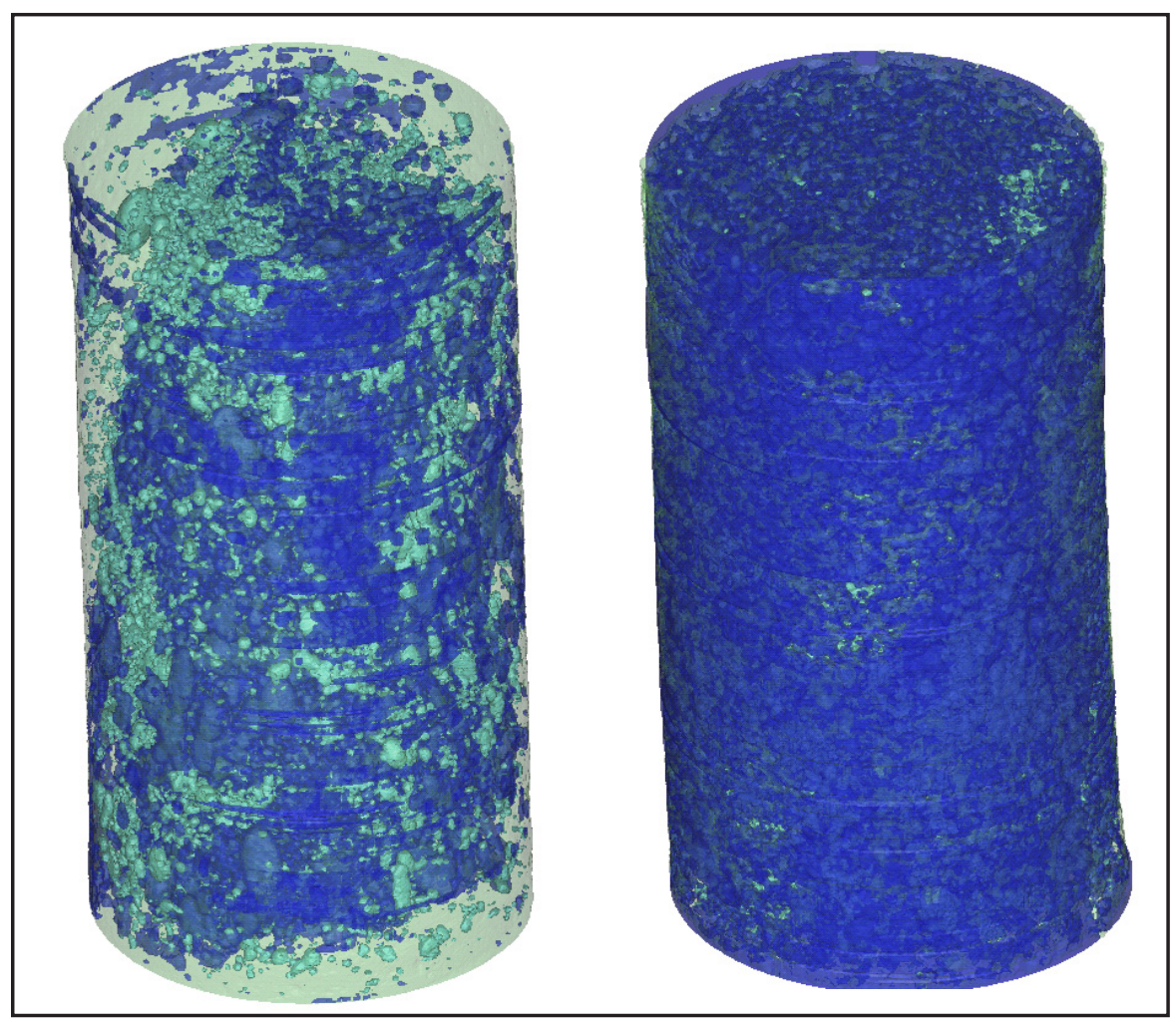

Figura 4. Reconstrucción en 3D de los andamios (Izquierda: Cemento; Derecha: Vidrio). Poros interconectados en oscuro, poros cerrados en claro y fase sólida en gris.

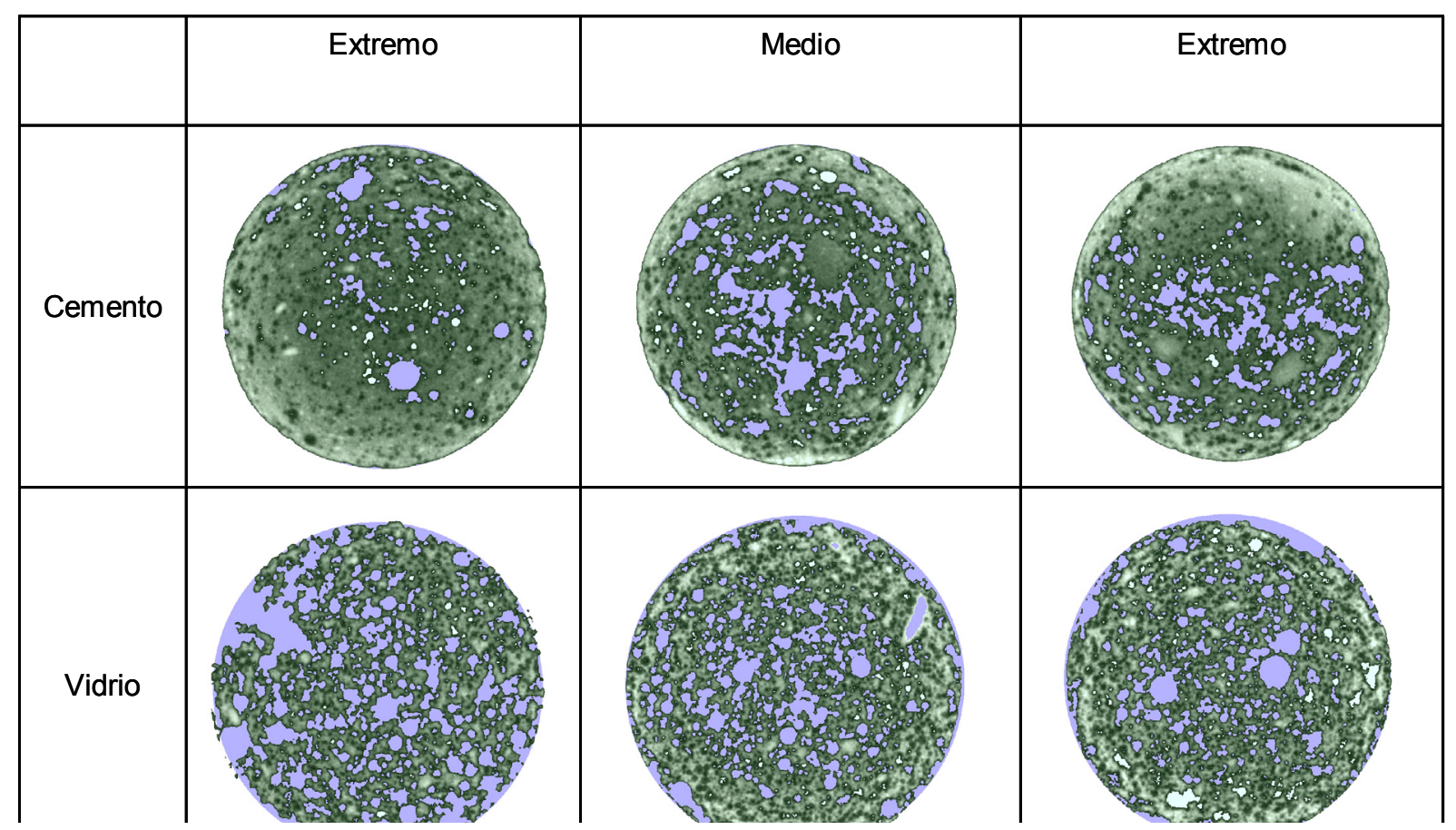

Figura 5. Cortes transversales de los andamios. Poros interconectados en gris, poros cerrados en blanco y fase sólida en oscuro. 
La forma de los poros parece ser esférica al observar los cortes transversales de ambas muestras (Fig. 5), sin embargo, en los cortes longitudinales (Fig. 6 y Fig. 7) se observan formas alargadas tendiendo más a elipses que a esferas.

Para determinar los parámetros del mallado de superficie adecuados para simular la estructura de los andamios en modelos de EF se utilizó el andamio de cemento. A medida que se disminuye la calidad de la malla superficial, se disminuye el número de triángulos, pero la malla se aleja de la superficie del andamio (Fig. 8) y el volumen aumenta (Tabla 2). La malla de calidad alta tiene más del triple de triángulos que la malla de calidad media y su diferencia en volumen es de 3\%. La malla de calidad media tiene 3,5 veces el numero de triángulos que la malla de calidad baja y su diferencia en volumen es del $7 \%$, respecto al volumen de la

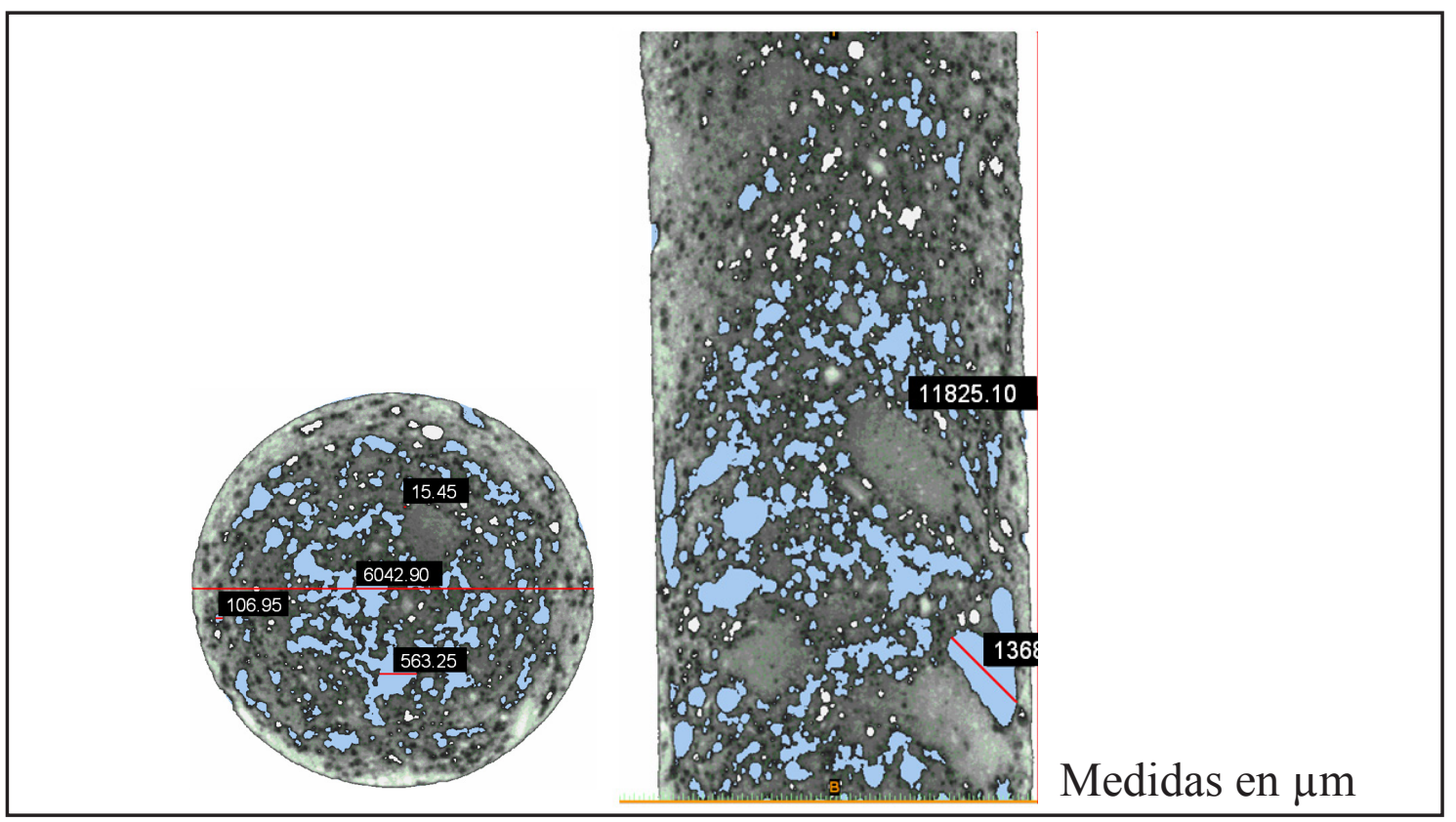

Figura 6. Cortes transversal y longitudinal y medida de algunos poros del andamio de cemento. Los poros no interconectados son de color blanco.

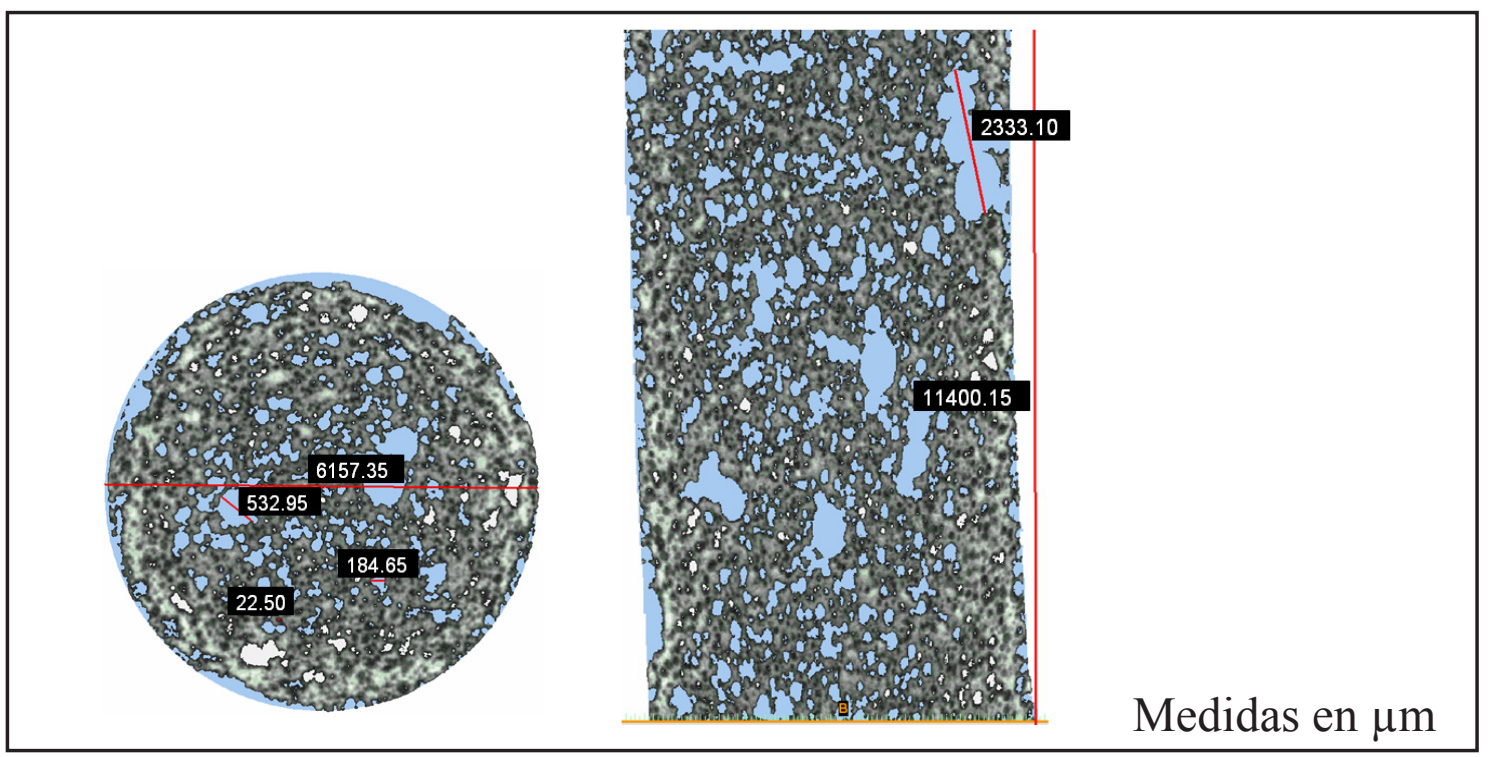

Figura 7. Cortes transversal y longitudinal y medida de algunos poros del andamio de vidrio. Los poros no interconectados son de color blanco. 
máscara utilizada para generar la malla. A medida que disminuye la calidad de las mallas, se pierde información en el caso de paredes delgadas o poros pequeños (Fig. 8).

En el mallado tridimensional para la fase sólida y líquida realizado en Patran se aprecia que la geometría externa empleada para la fase líquida simula los tubos de una cámara de perfusión en la que un andamiaje está sujeto a un flujo de perfusión. El número de elementos para cada mallado se muestra en la tabla 3 .

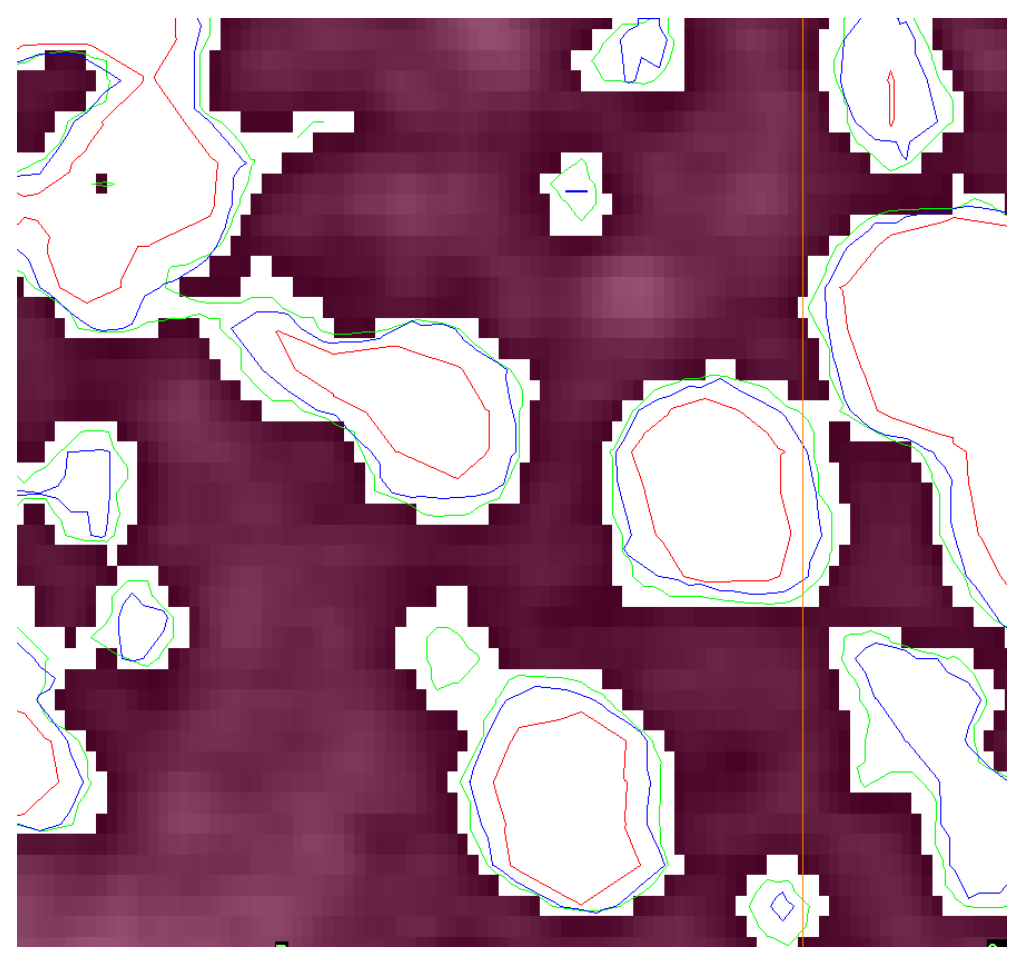

Figura 8. Corte transversal de la reconstrucción del andamio de cemento. Contorno de las mallas de superficie de la fase sólida (las líneas representan diferentes calidades de mallado).

\begin{tabular}{cccc}
\hline $\begin{array}{c}\text { Calidad de } \\
\text { mallado }\end{array}$ & $\begin{array}{c}\text { Número de triángulos } \\
{[\mathbf{x ~ 1 0}]}\end{array}$ & Volumen $\left(\mathbf{m m}^{3}\right)$ & $\begin{array}{c}\text { Diferencia de volumen } \\
\text { relativo a la mascara }\end{array}$ \\
\hline Máscara & & 278,45 & \\
Alta & 25,99 & 292,63 & $5,09 \%$ \\
Media & 8,22 & 301,30 & $8,20 \%$ \\
Baja & 2,32 & 321,33 & $15,40 \%$ \\
\hline
\end{tabular}

Tabla 2. Mallas de superficie de la fase sólida del andamio de cemento.

\begin{tabular}{ccc}
\hline Material & $\begin{array}{c}\text { sólidos (tetraedros) } \\
{\left[\mathbf{x} \mathbf{1 0}^{3}\right]}\end{array}$ & $\begin{array}{c}\text { Fluido (tetraedros) } \\
{\left[\mathbf{x 1 0 ^ { 3 } ]}\right.}\end{array}$ \\
\hline Cemento & 636,18 & 174,71 \\
Vidrio & 711,35 & 124,10 \\
\hline
\end{tabular}

Tabla 3. Número y tipo de elementos en los mallados tridimensionales de elementos finitos. 


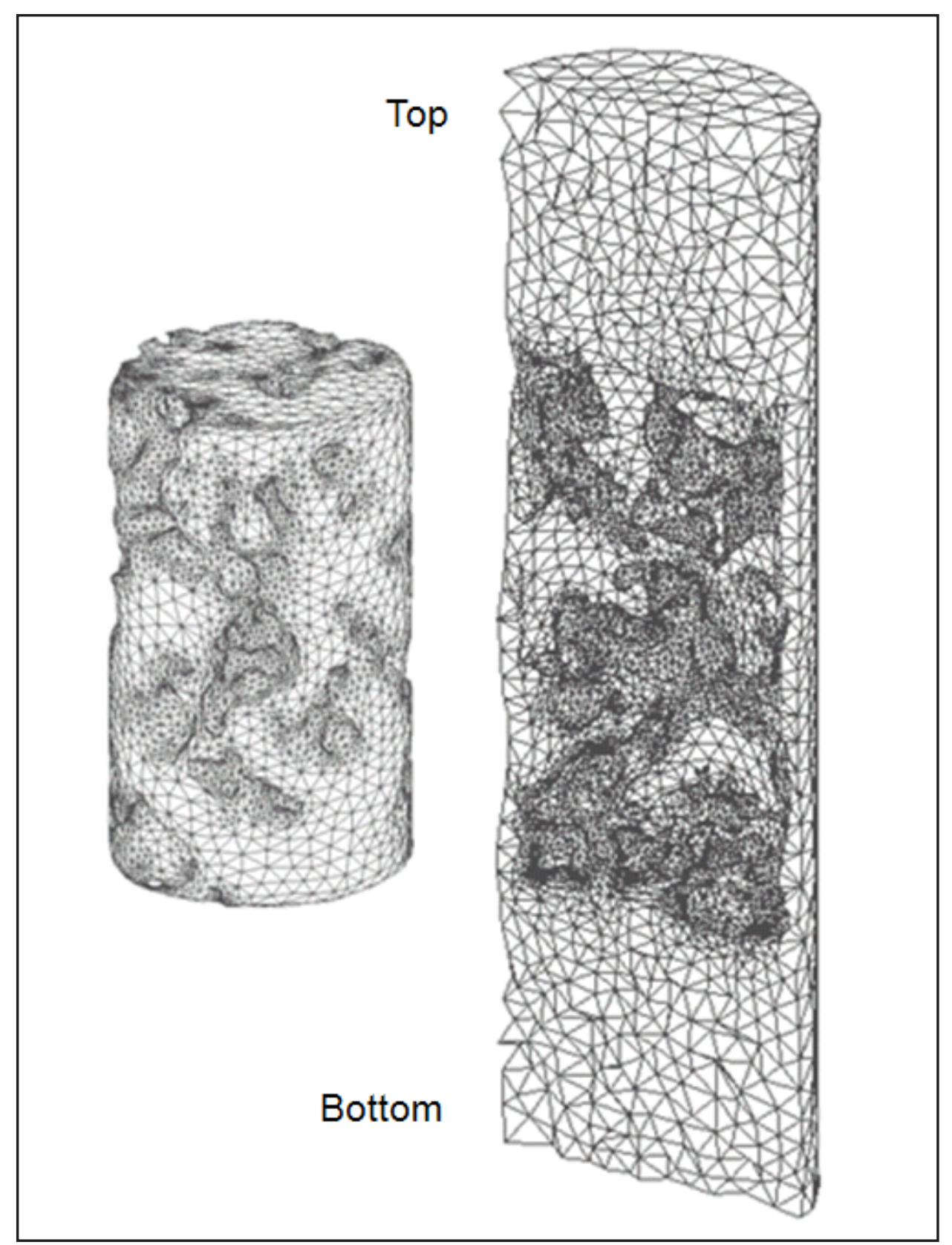

Figura 9. Mallado tridimensional para el andamio de cemento.

\section{Discusión}

Las reconstrucciones computacionales permiten calcular la porosidad, la interconectividad de los poros y el área superficial específica en los andamios además de hacer cortes de secciones trasversales y longitudinales para examinar el perfil, la distribución, la interconectividad y la forma de los poros. La macroporosidad del andamio de cemento calculada es de $18 \%$ y la del andamio de vidrio de $23 \%$. Estudios de porosimetría de andamios de estos mismos materiales reportan una macroporosidad del 37,1\% para el cemento y del $40 \%$ para el vidrio. La resolución de $\mu$ TAC utilizada es de $7,8 \times 7,8 \times 12,2 \mu \mathrm{m}$, esto afecta la precisión de los resultados dado que poros de menor dimensión no son detectados. Sin embargo, se sabe que el diámetro de poro mínimo requerido para osteoconducción es de $100 \mu \mathrm{m}$ [10].

El área superficial específica calculada para el andamio de cemento es de $4,87 \mathrm{~mm} 2 / \mathrm{mm} 3$ y para el de vidrio de $6,85 \mathrm{~mm} 2 / \mathrm{mm} 3$. Estos valores son similares a los reportados para andamios de hidroxiapatita $(7,02 \mathrm{~mm} 2 / \mathrm{mm} 3)$ y titanio $(4,25$ $\mathrm{mm} 2 / \mathrm{mm} 3)$ [3]. Se sabe que el área específica del hueso trabecular varía entre 13,12 and $23,73 \mathrm{~mm} 2 /$ 
$\mathrm{mm} 3$ [11]. Esta diferencia sugiere que el area superficial de los andamios estudiados podrían no ser suficiente para la adhesion, la proliferación y la diferenciación celular.

Con el programa Mimics, a partir de las reconstrucciones en 3D no se puede calcular la distribución del tamaño de los poros, sin embargo, realizando una evaluación visual se nota que en la muestra de vidrio tanto el tamaño de los poros como su distribución dentro del andamio son más homogéneos que en la muestra de cemento, en donde se encuentran poros de tamaño muy grande en algunas zonas del andamio y zonas sin porosidad. La diferencia entre las dos muestras al calcular la porosidad y la interconectividad no es muy grande, sin embargo, los cortes transversales de las reconstrucciones muestran diferencias importantes en la estructura de los materiales.

Se observa que el andamio de vidrio tiene mayor porosidad, mayor interconectividad y mayor área superficial que el andamio de cemento. Desde el punto de vista estructural, para ingeniería de tejidos sería mejor el andamio de vidrio que el andamio de cemento, dado que el medio con las células, los nutrientes y el oxigeno tendría más espacio para fluir, y las células tendrían más espacio para proliferarse y generar nuevo tejido. Adicionalmente, al aplicar cargas mecánicas en los andamios, la distribución de esfuerzos y deformaciones sería más homogénea en la muestra de vidrio que en la de cemento debido a la distribución de los poros y de su tamaño.

Mallas para modelos de EF que simulan la estructura real de los andamios fueron obtenidas. Dado que la diferencia en volumen entre la malla en calidad alta y la en calidad media es solo del $3 \%$ respecto al volumen original de la máscara, y que para realizar una malla en calidad alta se necesita más del triple de los elementos que en calidad media, se recomienda utilizar esta última. La malla generada en calidad baja no es recomendada.

En general es más complicado obtener mallas de tetraedros que mallas de hexaedros, en las que cada elemento se genera directamente a partir de los voxels $[12,13]$. Sin embargo, utilizando el software Mimics se generan automáticamente mallas cerradas de triángulos de la superficie de las máscaras que se utilizan para generar mallas volumétricas de tetraedros utilizando el programa Patran (MSC Software). La mayor dificultad al generar estas mallas consiste en que en las paredes de material muy delgadas aparecen triángulos intersecados y/o bordes libres. Para poder generar una malla de tetraedros, la malla de triángulos debe encerrar perfectamente el volumen que se quiere mallar, por lo tanto los triángulos intersecados se deben arreglar y los bordes libres se deben cerrar, ambos procesos se realizan manualmente.

A pesar de esta dificultad, las mallas de tetraedros representan mejor estructuras amorfas con un menor número de elementos y nodos, lo que se traduce en menor costo computacional al realizar los cálculos de EF. Para el caso del andamio de cemento estudiado se obtiene una malla superficial de 8,2 millones de elementos (mallado en calidad media); esta malla generaría una malla de 123 millones de tetraedros aproximadamente, suponiendo que todos los tetraedros son equiláteros. Utilizando una malla de hexaedros se tendría un total de 330 millones de elementos.

La posibilidad de generar modelos de EF que simulan la estructura real de los andamios, permite además analizar las propiedades biomecánicas de los materiales y determinar los estímulos mecánicos específicos que percibirían las células en cada punto del material. Dado que el método de obtención de imágenes no destruye las muestras, hace posible comparar los estudios de materiales in sílice con los estudios in vitro.

\section{Conclusiones}

Las reconstrucciones computacionales en 3D de los andamios a partir de $\mu$ TAC permiten examinar minuciosamente la estructura interna del material. Información sobre la porosidad, la distribución de los poros dentro del material, el tamaño de los poros y el área superficial que es difícil obtener mediante otros métodos, es obtenida sin destruir las muestras. Información sobre esfuerzos y deformaciones en las paredes internas del material puede ser obtenida a partir de modelos de EF. Esta información contribuye con el desarrollo de biomateriales para la ingeniería de tejidos, en donde las propiedades estructurales y mecánicas son de gran importancia.

\section{Referencias}

1. Lanza R., Langer R., and Vacanti J. (2000) Principles of Tissue Engineering, Academic Press, 2nd edition. Part II: In Vitro Control of Tissue Development. Tissue Engineering Bioreactors, L.E. Freed and G. Vunjak-Novakovic.

2. Ratner B.D., Hoffman A.S., Schoen F.J., Lemons J.E. (2004) Biomaterials Science: an introduction to materials in medicine. Academic Press, 2nd edition.

3. Van Cleynenbreugel T., Schrooten J., Van Oos- 
terwyck H., Vander Floten J. (2006) Micro-CTbased screening of biomechanical and structural properties of bone tissue engineering scaffolds. Med Bio Eng Comput 44:517-525.

4. Knackstedt M.A, Arns C.H, Senden, T.J, Gross K. (2005) Structre and properties of clinical coralline implants measured via 3D imaging and analysis. Biomaterials 27:2776-2786.

5. Saey Tuan H., Hutmacher D.W. (2005) Application of micro $\mathrm{CT}$ and computation modelling in bone tissue engineering. Computer-Aided Design 37: 1151-1161.

6. Jaecques S.V.N., Van Oosterwyck H., Muraru L., Van Cleynenbreugel T., De Smet E., Wevers M., Naert I., Vander Sloten J. (2004). Individualised, micro CT-based finite element modelling as a tool for biomechanical analysis related to tissue engineering of bone. Biomaterials 25 1683-1696.

7. Lacroix D., Château A, Ginebra M.P., Planell J.A. (2006) Micro-Finite element models of bone tissue-engineering scaffolds. Biomaterials 27:5326-5334.

8. Almirall, A., Delgado, J.A., Ginebra, M.P., Planell, J.A. (2004) Effect of albumen as proteinbased foaming agent in calcium phosphate bone cement. Key Eng Mater; 254-256:253-256.

9. Avila, G., Martínez, S., Del Valle, S., Ginebra, M.P., Planell, J.A. (2005) Alcobe X. Study of porous glass ceramic made by foaming egg white. In: Proceedings of the international conference on porous ceramic materials, Bruges, Belgium, 20-21 October 2005.

10. Karageorgiou V., Kaplan D. (2005) Porosity of 3D biomaterial scaffolds and osteogenesis. Biomaterials 26(27):5474-5491.

11. Hildebrand T, Laib A, Müller R., Dequeker J. and Rëgsegger P. (1999) Direct Three-Dimensional Morphometric Analysis of Human Cancellous Bone: Microstructural Data from Spine, Femur, Iliac Crest, and Calcaneus. J Bone Miner Res 14:1167-1174.

12. Van Rietbergen B., Weinans H., and Huiskes R. (1996) Computational strategies for interactive solutions of large FEM applications employing voxel data. International Journal for numerical methods in engineering 29: 2743-2767.

13. Viceconti M., Davinelli M., Fulvia T., Capello A. (2004) Automatic generation of accurate subject-specific bone finite element models to be used in clinical studies. J Biomech 37:1597-1605. 